\title{
Issues on VMAT QA Program with EBT3 Radiochromic Films: An improvement proposal
}

\author{
Dal Col A. H. ${ }^{1}$, Nagao A. ${ }^{1}$, Santos W. A. P. ${ }^{2}$, Pena G. P. ${ }^{3}$, Pelosi E. L. ${ }^{4}$, \\ Neves-Junior W. F. P. ${ }^{4}$, Haddad C. M. K. ${ }^{4}$ \\ ${ }^{1}$ Radiotherapy Department/ Sírio Libanês Hospital, São Paulo, Brazil \\ ${ }^{2}$ Radiotherapy Department/ Santa Paula Hospital, São Paulo, Brazil \\ ${ }^{3}$ Radiotherapy Department/ Radiotherapy Institute of Taguatinga, Taguatinga, Brazil \\ ${ }^{4}$ Radiotherapy Department/ Sírio Libanês Hospital, São Paulo, Brazil
}

\begin{abstract}
Resumo
O filme radiocromico EBT3 é renomado no campo da física médica devido sua verificação de dose para programas de Garantia de Qualidade (GA) em radioterapia de intensidade modulada (IMRT). Entretanto, é sabido que programas de GA, nos quais incluem estes filmes, são caros e requerem, relativamente, muito tempo para sua execução. Além do mais, nota-se que dosimetria com filmes EBT3 vem apresentando perda de acurácia. Dessa forma, avaliou-se isto, o tempo gasto em todo processo, bem como o custo-benefício de tal programa e é sugerido formas de melhorar este processo. Um estudo retrospectivo foi realizado sobre planejamentos de VMAT, mensurando a quantidade de casos que foram aprovados pela análise gama absoluta. Além disso, objetivando verificar o envelhecimento entre lotes, as curvas de calibração foram comparadas baseando-se na data de fabricação do lote. Por outro lado, com analises de dosimetria multicanal e canal único, analisou-se as curvas de saturação em um período de até $35 \mathrm{~h}$ após a irradiação. Aa análises gama retrospectivas mostraram que, aproximadamente, $23 \%$ do total de casos de VMAT não foram aprovados por análise gama absoluta. Foi visto que a data de fabricação influencia a resposta de dose do filme, o que mostra, de forma conservadora, a necessidade de uma curva de calibração para cada caixa de filme. Para analise multicanal, como esperado, o canal vermelho foi o mais sensível para doses de até $5 \mathrm{~Gy}$. Além do mais, reforçou-se que a resposta de dose é uma função direta do nível de dose tanto para multi quanto para canal único. Dessa forma, optou-se por um intervalo de tempo de 12h-16h após irradiação, com variação na resposta de dose menor que $2 \%$. Por fim, verificou-se, baseado em nossa rotina, que houve, aproximadamente, $23 \mathrm{~h} / \mathrm{mês}$ dedicado em nosso programa de GA com filme e um custo direto de US\$20.000,00/ano.
\end{abstract}

Palavras-chave: Filme Gafchromic; Curvas de Calibração; Garantia de Qualidade Paciente Específico; Instabilidade; Custo-benefício.

\begin{abstract}
EBT3 radiochromic film is renowned in medical physics field due its dose verification for Quality Assurance (QA) program in intensity-modulated radiotherapy (IMRT). However, it is known that QA programs, which include these films, are expensive and relatively time-consuming. Furthermore, it was noted that dosimetry with EBT3 film has been suffering with lack of accuracy. In that way, it was evaluated its possible dosimetric inaccuracy, the time expenditure in the whole QA process, as well as the cost-benefit of such a program and it is suggested efforts to improve this process. A retrospective study was performed on VMAT plans, rating how many cases got success by absolute dosimetric Gamma analysis. Furthermore, in order to verify the film inter-lot aging, the calibration curves were compared based on lot fabrication date. On the other hand, with single- and multichannel dosimetric analyses, further trials were performed over the post-irradiation saturation curves up to 35 $h$ after irradiation. The retrospective Gamma analyses exhibited that about $23 \%$ of the total VMAT cases did not passed by absolute Gamma evaluation. It was seen that the fabrication date influences the dose response, which, conservatively speaking, prerequisites a calibration curve for each film box. For the multichannel analyses, as excepted, the red channel sensitivity was the highest for doses up to $5 \mathrm{~Gy}$. Moreover, it was reinforced that the dose response is a direct function of dose level for both types of analyses. In that way, it was chosen a post-irradiation time interval of $12 h-16 h$, with dose response variation criteria less than $2 \%$. Finally, it was verified, based on our routine, that there were about 23h/month expended in our film QA program and directly costs bordering US\$20,000.00/year.
\end{abstract}

Keywords: Gafchromic film; Calibration Curves; Patient Specific Quality Assurance; Instability; Cost-Benefit

\section{Introduction}

Radiochromic film has proven to be a great dosimetric tool for Patient Specific Quality Assurance (PSQA) program in the Intensity Modulated Radiotherapy (IMRT) technique. Initially, EBT and
EBT2 Gafchromic films were used in such procedures ${ }^{1,2,3}$. Since then, improvements have been performed on these films in order to minimize its sensitivity to visible light exposure, the dependence on face up/down during scanning process, and the 
Newton-rings artifacts ${ }^{4}$. In fact, today there is the EBT3 radiochromic film, which accomplishes, among others, these characteristics.

The Volumetric Modulated Arc Therapy (VMAT) QA program accomplishes analysis based on Ionization Chamber, film dosimetry, and Portal Dosimetry verification. However, it has been noticed that the QA program for VMAT plans based on EBT3 radiochromic films is not as good as before in terms of accuracy and reproducibility. Against these inconsistences, a project application was proposed in order to overcome these issues.

A Project Application aims to verify the reality, identify issues, selects the problem descriptors and, then, elaborates and watch intervention proposals. In that way, this work verifies inconsistencies on VMAT QA program with EBT3 films based on retrospective analysis of films dosimetric outcomes and come up with improvements for the whole process.

\section{Materials and Methods}

\subsection{EBT3 Radiochromic film}

In this study the GAFCHROMIC EBT3 films were used, whose original dimensions are $25.4 \times 20.3 \mathrm{~cm}^{2}$. These films consist of a $27 \mu \mathrm{m}$ thickness single active layer, which lies between two $120 \mu \mathrm{m}$ thickness visible light transparent layers and have been commonly used for radiotherapy dosimetry ${ }^{5}$. These films have been selling in a box with 25 sheets. At this time, the $68^{\text {th }}$ film box has been used in our institution. In addition, all films were handled following the recommendations remarked by the manufacturer, as well as, the AAPM TG-55 ${ }^{6}$ (e.g., considering the dependences with scanner orientation ${ }^{7}$, response to high-dose ${ }^{8}$, ambient light sensitivity ${ }^{8}$, temperature dependence ${ }^{8,9}$ ).

For the PSQA program, the sheets size pattern is set to $25.4 \times 20.3 \mathrm{~cm}^{2} ; 25.4 \times 12 \mathrm{~cm}^{2} ; 25.4 \times 10 \mathrm{~cm}^{2}$ and $25.4 \times 8 \mathrm{~cm}^{2}$, as a function of the dose distribution size predicted by the Treatment Planning System (TPS). In addition, for calibration films, the size of 25.4 $\times 20.3 \mathrm{~cm}^{2}$ has been used in order to accomplishes the eight steps of calibration dose levels (Figure 1).

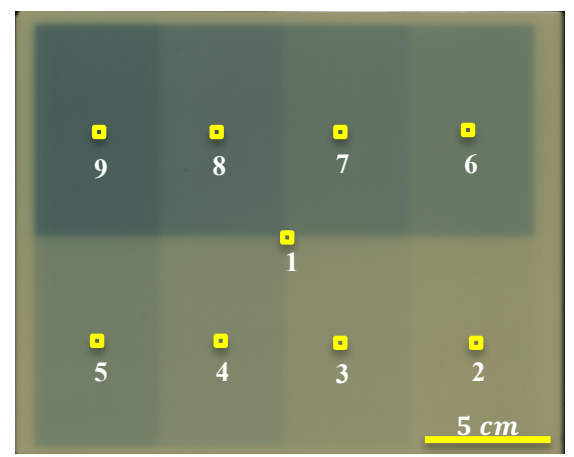

Figure 1. Digitized calibration step film with doses up to $5 \mathrm{~Gy}$ irradiated at $2 \mathrm{~cm}$ depth in solid water and the $0.5 \times 0.5 \mathrm{~cm}^{2}$ regions of interest used to generate the calibration curves. Region 1 level is taken before film irradiation (background).

\subsection{Irradiation Protocol}

For all films irradiation (PSQA and calibration), a same solid water setup is used. The setup consists of 12 plates of $1 \mathrm{~cm}$ thickness each and the lonization Chamber (I.C.) insert with $2 \mathrm{~cm}$ thickness, summing up $14 \mathrm{~cm}$ (concomitant measurement with I.C. occurred whenever it was possible).

For calibration, two step films from each box were irradiated in a $6 \mathrm{MV}$ TrueBeam ${ }^{\mathrm{TM}}$ at dose levels - first one up to $5 \mathrm{~Gy}$ and the second one up to $25 \mathrm{~Gy}$. However, in this study, evaluating only the 5 Gy step film was enough, since it is known that a similar film dose response is expected up to $40 \mathrm{~Gy}^{1,4}$. These films have eight dose levels (besides the background) which were irradiated in solid water setup under $2 \mathrm{~cm}$ depth (or 2 plates). This protocol has been performed immediately after the Linear Accelerator (LINAC) monthly dosimetry, in order to take into account the machine output factor for further dose corrections.

The PSQA radiochromic film irradiations were done at the TrueBeam $^{\mathrm{TM}}$ and NovalisNTx ${ }^{\mathrm{TM}}$, depending on each VMAT plan. All cases used $6 \mathrm{MV}$. The films were disposed at a depth in solid water that represents a trustful and representative 2D-dose distribution of the treatment plan.

\subsection{Scanning and Dosimetric Analysis Procedure}

All the VMAT-PSQA films in this study were scanned through VIDAR Dosimetry Pro Advantage ${ }^{\mathrm{TM}}$. This scanner has a set of white light LEDs. The light source is very close to the film, thus the effects of light scattering by the film-digitizer measurement system are minimized. Moreover, this film digitizer accomplishes self-light calibration, which reduces some scanning artifacts ${ }^{10}$. All of these characteristics result in an efficient single channel film dosimetry.

Further analyses over calibration films were performed with EPSON 11000XL scanner. This is a reflective film digitizer with a spatial resolution of up to $2400 \mathrm{dpi}^{11}$. As it has a three channel CCD detector, it was possible to perform a multichannel dosimetric evaluation of the EBT3 step films, which has demonstrated higher agreement with the experimental measurements and with the treatment planning system than the single channel analyses ${ }^{12,13}$.

PSQA EBT3 films were scanned through OmniPro I'mRT'TM software (which has been used to film dosimetric analysis, as well) at 24 hours postirradiation and after 2 minutes of scanner light calibration. For EPSON scanner, the EPSON Scan v.3.49A software was used considering 2 minutes of scanner warm up. All films were handled with gloves in order to avoid scanning artifacts due fingerprints and all of them were digitized in landscape orientation - relative to the scanner detector array - in the center of each scanner ${ }^{1}$. This orientation, as well as the location of the film positioning in VIDAR and EPSON scanner were set based on studies that had already been performed in this institution, as well. 
The PSQA dosimetric evaluation laid on Gamma function results, with $3 \%, 3 \mathrm{~mm}$ criteria $^{14}$. The Gamma analysis is approved when $96 \%$ or more pixels reach the Gamma function value less than, or equal, to 1. Moreover, it was desirable that every plan gets approval by absolute analysis at first. Whether absolute analysis was not successful, a second kind of analysis would be performed, where the dose difference between the two dose distributions are normalized keeping the absolute difference as measured with I.C. - method that will be referred as I.C. cross calibration. At last, as a third option, the relative analysis would be done if none of the preceding analysis succeeded.

The bottom line is that, in order to approve a PSQA at our institution, it is required - as a least - one reliable absolute point dose measurement (i.e. I.C.) to pass and an evidence that the $2 \mathrm{D}$ shape (i.e. relative) of the measured dose distribution matches calculation. Thus, given the low consistency of the film absolute calibration amongst the batches and within a same batch, it has been decided that either a cross calibration with the I.C. result or even a full relative comparison are necessary in order to evaluate a PSQA neglecting these known issues with films.

The calibration step film had been irradiated for every new film box. For this purpose, eight equal 0.5 $\mathrm{cm}$ regions of interest ( $\mathrm{ROI}$ ) had been disposed at the center of each rectangle dose levels showed in Figure 1 (in order to minimize the scattered dose from the adjacent dose levels) and the ROI number 1, which corresponds to background value (film before irradiation). The Analog-to-Digital Converter (ADC) number and the Net Optical Density (NOD) mean values (for VIDAR and EPSON, respectively), inside the ROls had been measured and mapped into mean dose levels of about $0,0.17,0.48,0.98,1.57,2.07$, $2.80,3.72$ and 5.04 Gy (corrected according to the machine output factor in the day of step film irradiation).

The nine points in calibration curve have been interpolated through polynomial fitting, whose the order has been set in order to minimize the total difference between the interpolated and original data.

\subsection{VMAT Retrospective Plans Gathering}

The medical physics' department possesses a database bearing all VMAT plans that have been performed since 2011. For the purpose of this study, only plans related to calibration curves performed on TrueBeam $^{\mathrm{TM}}$ (from oct-2016 to feb-2018) were evaluated. The whole RapidArc ${ }^{\mathrm{TM}}$ dosimetric analyses were assembled by registration date. An analysis was performed in order to know the rate of plans that were approved by absolute, relative and I.C. cross calibration methods, for each month. At this department, an EBT3 film box lasts about 30 days.

All Gamma analysis were splitted among five principal groups, which accomplish Head and Neck $(\mathrm{HN})$, Rectum and Colon (RC), Prostate $(P)$ and Stereotactic procedures as Stereotactic Body Radiotherapy (SBRT) and Stereotactic Radiosurgery (SRS). For these sites or techniques, the percentage of plans which got approval by absolute film analysis were compared with those that passed only by I.C. cross calibration and relative dosimetric evaluation. All in all, one can access the degree of reliability of EBT3 film dosimetry on VMAT Patient Specific Quality Assurance (PSQA) program.

\subsection{Inter-lot Film Response Variation}

For the purpose of evaluate the inter-lot ADC mean value differences related to EBT3 radiochromic films, a retrospective study over calibration curves was performed in order link to fabrication date of each box.

Once the intention was to evaluate inter-lot variance on film response, either $5 \mathrm{~Gy}$ or the $25 \mathrm{~Gy}$ step films could be used for this comparison, as mentioned in section 2.2. In this way, the 5 Gy step film was chosen (once the majority of the plans lies on doses up to this value) and the non-interpolated curves were compared, in order to get rid of small errors associated with polynomial interpolation. For the most of film boxes, the fabrication date could be determined, but for a minority this information was missing.

\subsection{Time Expended and Costs}

It was evaluated the time expended in the whole process of the PSQA based only on the time dedicated to EBT3 radiochromic film procedure. The time dedicated to this task was divided in preirradiation, during irradiation and post-irradiation time. It was measured regardless of the time related to the process that would already exist with no film irradiation (e.g. with I.C. or Portal Dosimetry only). For example, the pre-irradiation process consists in cut and digitalize the film; During irradiation time accomplishes situation that film had to be irradiated independent of I.C; Post-irradiation time is related to film post-processing as scanning and Gamma Function analysis.

About costs, it was analyzed the direct outlay per year for the institution, considering the flux of one film box per month, and the indirect costs as well. For instance, estimate how many cases could be performed if the film based VMAT PSQA program was indicated only for specifics treatment plans.

\subsection{Step Film Post-Irradiation Study}

Two EBT3 step films up to 5 Gy level were irradiated with a $6 \mathrm{MV}$ in a Truebeam ${ }^{\mathrm{TM}}$ accelerator and then scanned (one for VIDAR and other for EPSON) in successive short time intervals in order to evaluate post-irradiation time development for each film digitizer. The repeated scanning process could be interfered in the outcomes, so it was guaranteed by Khachonkham et al. that it does not significantly influence film darkening due to multiple scans ${ }^{4}$. Everything was performed aiming a new time for postirradiation scanning, instead of $24 \mathrm{~h}$.

The two 5 Gy step films was digitized from 0 to $16 \mathrm{~h}$ after irradiation in an interval of $1 \mathrm{~h}$. Two more scan were performed at time of $24 \mathrm{~h}$ and $35 \mathrm{~h}$. The intention was evaluating the $A D C$ and NOD mean values 
difference between $12 \mathrm{~h}, 14 \mathrm{~h}$ and $16 \mathrm{~h}$ in order to reduce from $24 \mathrm{~h}$ to $14 \mathrm{~h}$ the post-irradiation scanning time. Furthermore, the EPSON and VIDAR evaluation was performed in order to possibly migrate from single channel analysis to multichannel, for reasons that has already mentioned in section 2.3.

To compare the ADC and NOD difference, $14 \mathrm{~h}$ was taken as the point of comparison. If dose levels (or ADC/NOD values) for $12 \mathrm{~h}$ and $16 \mathrm{~h}$ did not vary too much compared to $14 \mathrm{~h}$, it could be set as the optimal time window for post-irradiation scanning, once it would be a plateau in saturation curve. The percentage difference $\Delta(x)$ was calculated through Equation 1, which $\overline{A D C}(14 h)$ is the mean $A D C$ value for $14 \mathrm{~h}$ and $\overline{A D C}(x)$ is the same value for " $x$ " hours (in that case, $12 \mathrm{~h}$ or $16 \mathrm{~h})$.

$$
\Delta(x)=\frac{\overline{A D C}(14 h)-\overline{A D C}(x)}{\overline{A D C}(14)} \times 100 \%
$$

The same could be applied for NOD by replacing $\overline{A D C}$ for $\overline{N O D}$. Once there are studies stating that a variation of 2 to $3 \%$ in film response is acceptable ${ }^{1,4,6}$, it was chosen a limit of $2 \%$ of variation in ADC and NOD means values in that comparison for accepting the new after-irradiation time.

\section{Results}

A total of 421 VMAT plans were grouped in a set of graphics which can be clearly seen that the majority was approved by Absolute comparison (Figure 2-a). In this graphic, besides the frequency of cases, one can see the absolute number of cases in each month related to the Gamma analysis type. In a more detailed point of view, one can note that around $23 \%$ of the global cases do not get approval by this kind of analysis $(17 \%$ and $6 \%$ for I.C. Cross Calibration and Relative, respectively).

It can be noticed that, for HN and SBRT-SRS plans, the major number of cases reached the absolute analysis. For instance, only 4\% and 3\% (respectively) of plans had to be analyzed by relative evaluation and $16 \%$ and $12 \%$ (respectively) had to be evaluated by I.C. Cross Calibration analysis.

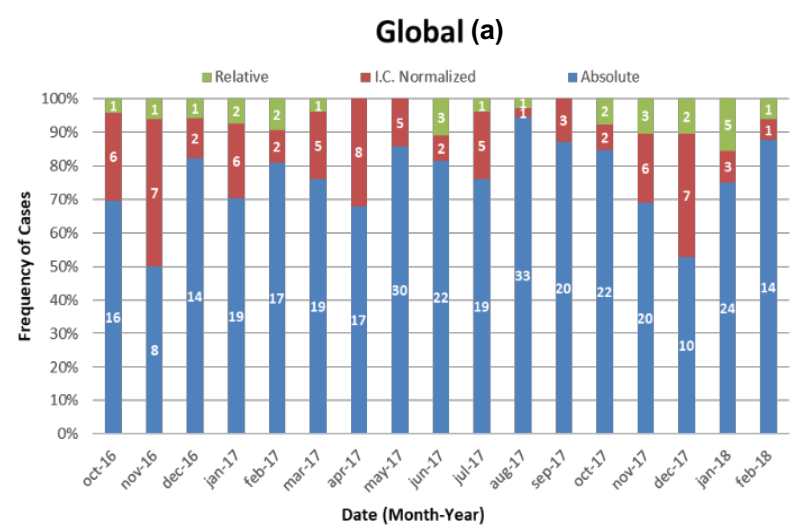

Figure 2 - Frequency and number of cases (inside the bars) for Global (a), Prostate (b), Head and Neck (c), SBRT-SRS (d) and Rectum and Colum (e) that were approved by Absolute, Relative and I.C. Normalized Gamma analysis for each month and year.

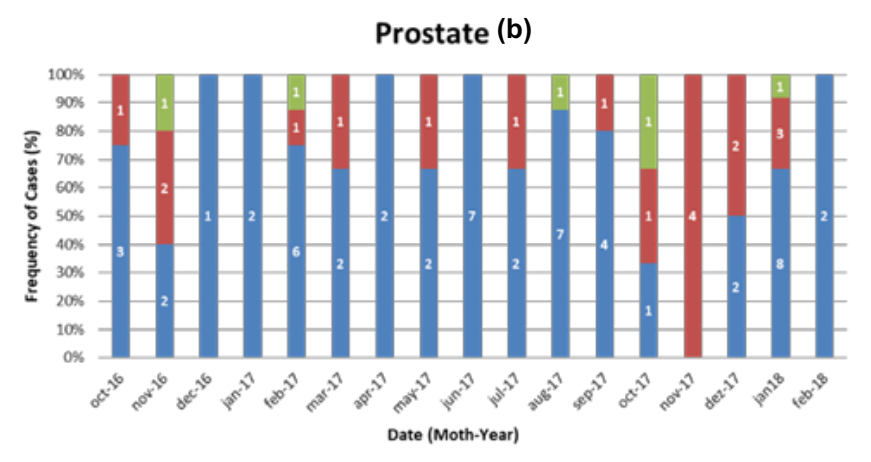

Head and Neck (c)
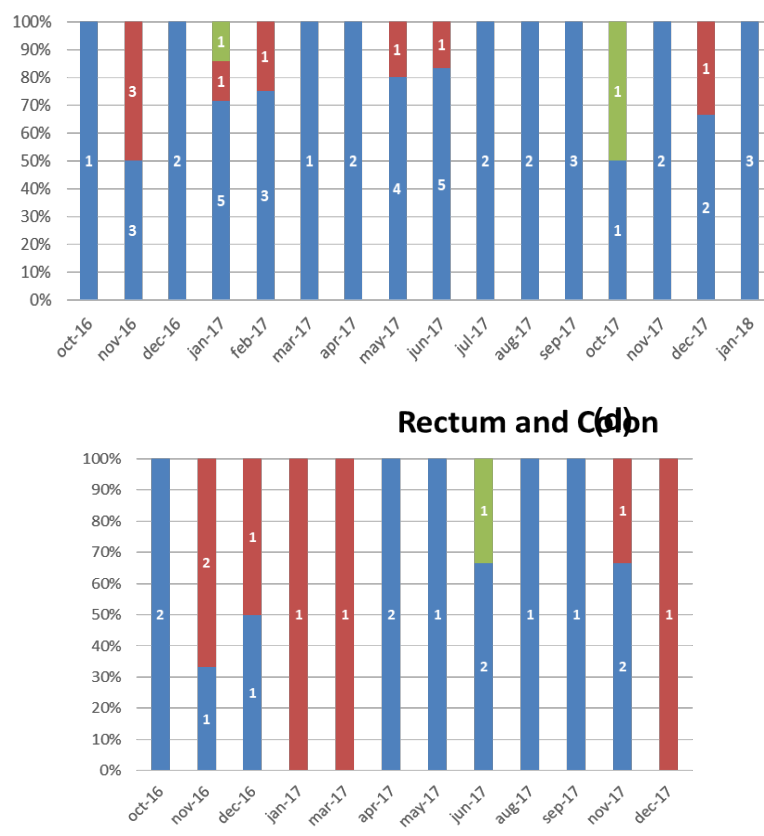

SBRT-SRS (e)

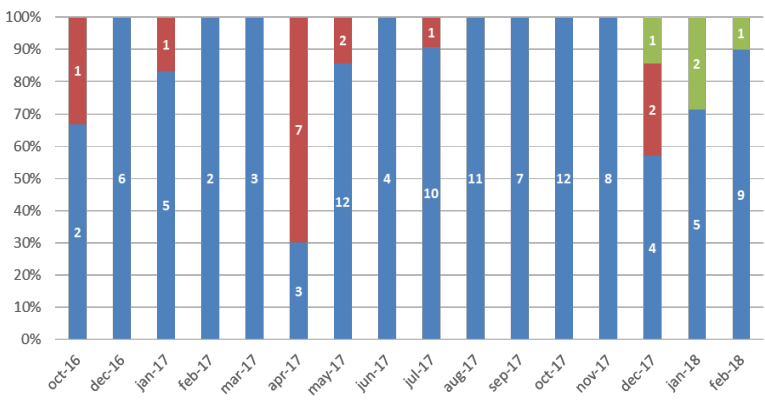

Figure 2 - Frequency and number of cases (inside the bars) for Global (a), Prostate (b), Head and Neck (c), SBRT-SRS (d) and Rectum and Colum (e) that were approved by Absolute, Relative and I.C. Normalized Gamma analysis for each month and year.

Nevertheless, for Prostate and RC plans, one can notice worse results: around $7 \%$ and $5 \%$ were approved by relative, and a total of $24 \%$ and $33 \%$ of plans got a successful analysis only through I.C. Cross Calibration

Once these PSQA film analyses had been mediated by calibration curves for each film batch, Figure 3 shows the eight response points for each one, which carry the LINAC output factor obtained in the day of step film irradiation. 
As seen in the Figure 3, there is a salient shift in ADC mean values for film boxes number 65,67 and 68 , which is verified that these batches were put on sale one year after the others. It is noticed that the output factor increased for these boxes, respectively. However, there are high output factors for the others, as well. On the other side, the film batch number 55 showed a relative dissociated behavior for ADC mean numbers from 4 to 9 levels. These showed lower values than its neighbors did.

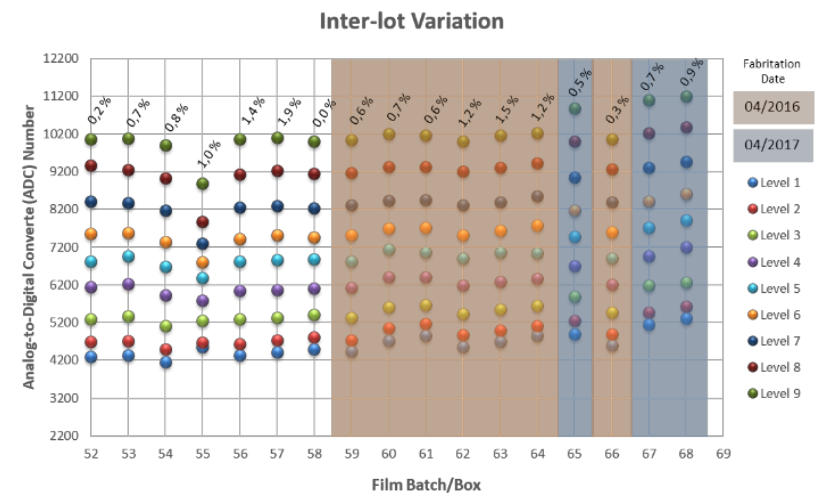

Figure 3-ADC mean levels used for each film batch calibration ranging from 52 to 68 . The salmon and light-blue background color indicate lot fabrication date: 04/2016 and 04/2017, respectively. The percentage related to each levels group is the output factor in the day of the monthly dosimetry.

The post-irradiation saturation study on step films was performed firstly for multichannel dosimetry in order to verify the sensitivity of red, green and blue channels during the time-development), which can be noticed in Figure 4. It is visible how the floating in the NOD values over time for red channel is attenuated relative to the two others. Furthermore, based on red channel, it can be seen (in Figure 5, as well) that for $14 \mathrm{~h}$, the step film reached its maximum of saturation for nearly all levels ranging from 2 to 9 . The ones which it did not occur were 2 and 3 (i.e. $95 \%$ and $98 \%$, respectively), that corresponds to mean doses of 0.17 and 0.48 Gy (which are the lowest and carry more uncertainty than the highest ones).

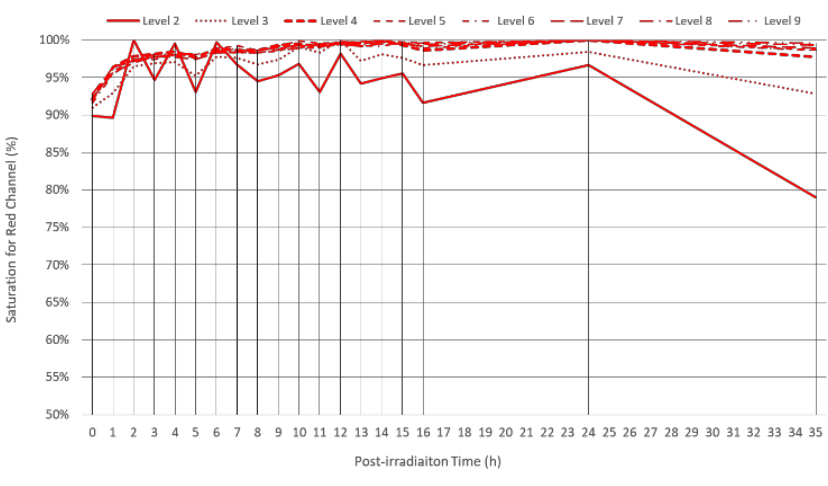

Figure 4 - Evaluation of Red, Green and Blue channel NOD variability for step film up to $5 \mathrm{~Gy}$. Percentage of saturation normalized to NOD máx of each level for all channels.
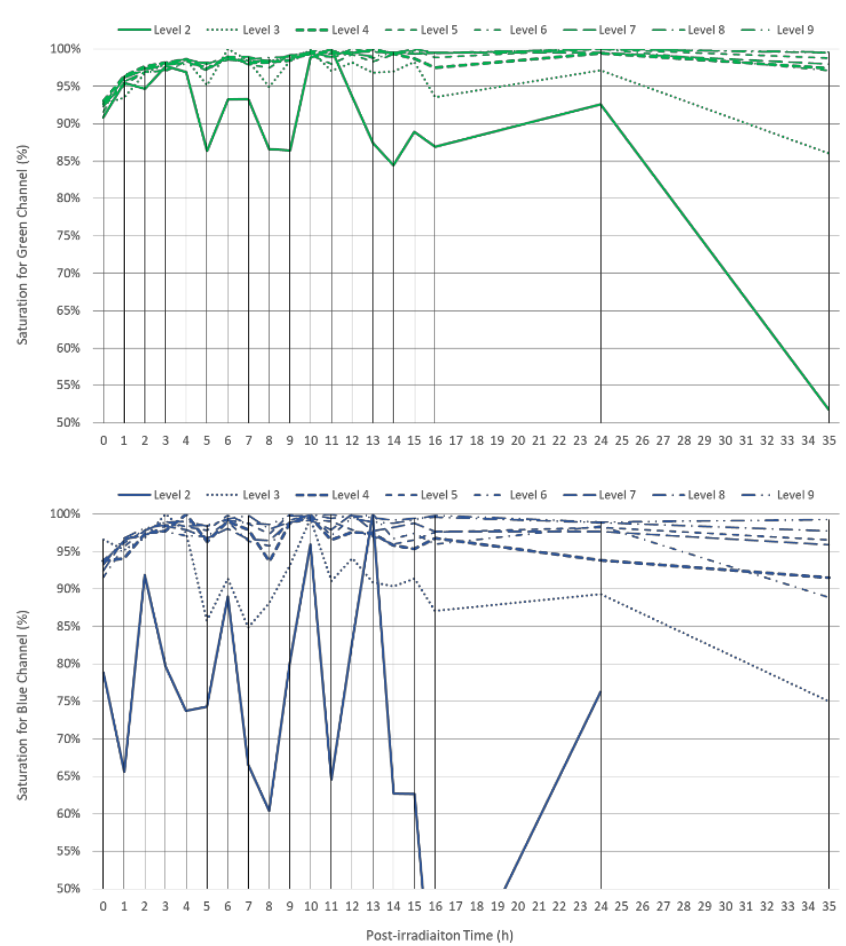

Figure 4 - Evaluation of Red, Green and Blue channel NOD variability for step film up to $5 \mathrm{~Gy}$, respectively. Percentage of saturation normalized to NOD máx of each level for all channels.

Figure 5 presents how dependent the timedevelopment of NOD is to dose level. The higher the dose delivered to EBT3 film, the more variation it suffers as time runs until saturation is reached. It can be seen that the maximum of saturation for levels ranging from 2 to 9 happens respectively at $2 \mathrm{~h}, 12 \mathrm{~h}$, $12 \mathrm{~h}, 10 \mathrm{~h}, 15 \mathrm{~h}, 14 \mathrm{~h}, 14 \mathrm{~h}$ and $13 \mathrm{~h}$ after irradiation. One can notice that an interval ranges of $12 \mathrm{~h}-16 \mathrm{~h}$ could be an optimal choice for post-irradiation scanning once it seems to be reached a plateau.

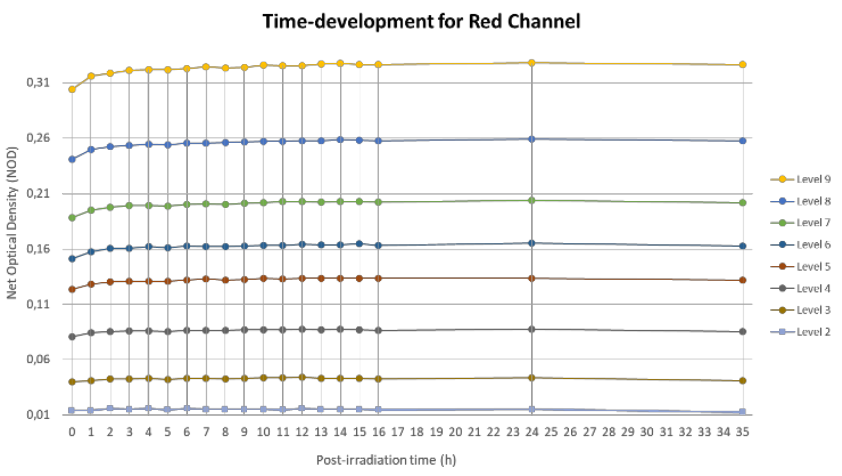

Figure $\mathbf{5}$ - Saturation of NOD for red channel from 0 to $35 \mathrm{~h}$ after step-film irradiation at each level, corresponding to dose levels up to $5 \mathrm{~Gy}$.

For VIDAR (single-channel digitizer), the saturation curve is shown in Figure 6. For level number 2, which corresponds to dose level around of $0.17 \mathrm{~Gy}$, the ADC saturation curve presents a random behavior up to $16 \mathrm{~h}$. However, it remained around $99 \%$ of saturation after this time, once that $100 \%$ was reached at $0 \mathrm{~h}$ after irradiation (an odd fashion). In the opposite, for the further levels, a plateau is reached around to $14 \mathrm{~h}$. 
Once the maximum saturation is reached at $14 \mathrm{~h}$, this post-irradiation time was chosen as being the optimal scanning moment to ascertain. However, it is essential to evaluate the differences in NOD and ADC outcomes for an interval of time around $14 \mathrm{~h}$. It was taken into account the earlier and later two hours from $14 \mathrm{~h}$, in order to accommodate the possible new digitalization time in our routine considering margins delays. The discrepancies calculated by Equation (1) are shown in Table 1.

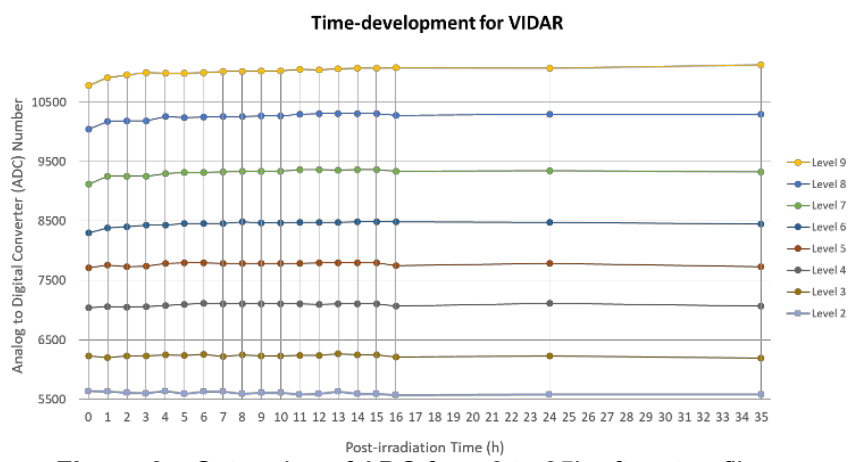

Figure 6 - Saturation of ADC from 0 to $35 \mathrm{~h}$ after step-film irradiation at each level, corresponding to dose levels up to $5 \mathrm{~Gy}$.

Table 1 - Evaluation of ADC and NOD stability for irradiated levels based on differences in these quantities for $12 \mathrm{~h}$ and $16 \mathrm{~h}$ relative to $14 \mathrm{~h}$.

\begin{tabular}{cccc}
\multicolumn{4}{c}{ relative to 14h. } \\
\hline \multicolumn{4}{c}{ VIDAR } \\
\hline $\begin{array}{c}\text { Dose } \\
\text { Level }\end{array}$ & $\Delta(12 \mathrm{~h}) \%$ & ADC $(14 \mathrm{~h})$ & $\Delta(16 \mathrm{~h}) \%$ \\
\hline $\mathbf{2}$ & 0.00 & 5590 & 0.34 \\
\hline $\mathbf{3}$ & 0.13 & 6250 & 0.58 \\
\hline $\mathbf{4}$ & 0.14 & 7109 & 0.48 \\
\hline $\mathbf{5}$ & -0.01 & 7797 & 0.60 \\
\hline $\mathbf{6}$ & 0.04 & 8485 & 0.00 \\
\hline $\mathbf{7}$ & -0.05 & 9362 & 0.29 \\
\hline $\mathbf{8}$ & -0.03 & 10303 & 0.22 \\
\hline $\mathbf{9}$ & 0.23 & 11068 & -0.11 \\
\hline \multicolumn{4}{c}{ EPSON (Red Channel) } \\
\hline Dose & $\Delta(12 \mathrm{~h}) \%$ & ADC $(14 \mathrm{~h})$ & $\Delta(16 \mathrm{~h}) \%$ \\
\hline $\mathbf{2}$ Lel & -3.50 & 0.02 & 3.40 \\
\hline $\mathbf{3}$ & -1.90 & 0.04 & 1.50 \\
\hline $\mathbf{4}$ & 0.19 & 0.09 & 1.30 \\
\hline $\mathbf{5}$ & 0.29 & 0.13 & 0.27 \\
\hline $\mathbf{6}$ & -0.32 & 0.16 & 0.20 \\
\hline $\mathbf{7}$ & 0.13 & 0.20 & 0.37 \\
\hline $\mathbf{8}$ & 0.39 & 0.26 & 0.32 \\
\hline $\mathbf{9}$ & 0.50 & 0.33 & 0.23 \\
\hline & \multicolumn{3}{c}{} \\
\hline
\end{tabular}

All differences lied below to $2 \%$ except for level 2 in red channel analysis. However, considering its low dose, the higher red channel sensitivity for levels of this magnitude and the favoring characteristic of Gamma function evaluation for low doses, this discrepancy seems not to have significant dosimetric impact over PSQA. Therefore, it may be reasonable setting the time interval of $12 \mathrm{~h}-16 \mathrm{~h}$ as an optimal postirradiation digitizing time instead of $24 \mathrm{~h}$, once the dose response actually remains the same during this period (there is a plateau).

In order to evaluate the amount of time expended in PSQA with EBT3, it was verified that the average of time dedicated to pre-irradiation procedure (e.g. background scanning, film cutting) lied about $5 \mathrm{~min}$.

Moreover, the mean time expended for irradiating the films was about $8 \mathrm{~min}$, besides of $20 \mathrm{~min}$, in average, for post-irradiation analysis. Considering a month like may-17 - which presented one of the biggest number of cases (Figure 2-a) - the routine requires around 9 pieces of film per week, it results in nearly 35 pieces of film sheets per month. In other words, around 23 hours are expended directly into PSQA program established with radiochromic film analysis.

The mean time for planning a Head and Neck, Prostate, Rectum and Colon, SBRT/SRS by the physics staff of our institution are shown in Table 2.

Table 2 - Average time dedicated for physics staff of the respective hospital for planning the respective sites/techniques.

\begin{tabular}{cc}
\hline Plan Type & Mean time dedicated (min) \\
\hline HN & 180 \\
P & 60 \\
RC & 90 \\
SBRT/SRS & 60 \\
\hline
\end{tabular}

If $23 \mathrm{~h}$ per month were dedicate only for planning, and the same planning rhythm was kept by the physics staff, one could obtain 8 more $\mathrm{HN}$ cases or, in the same way, 23 more plans of Prostate and SBRT/SRS or, in addition, 15 more RC cases. All in all, it would contribute indirectly to institution profit.

Nowadays, each film sheet costs around US $\$ 65.00$. Based on it, considering that about 25 film sheets are needed per month (as It was already seen in this work), thus, in one year, the institution would expend nearly to US $\$ 20,000.00$ only with films.

\section{Discussion}

This study examined the lack of stability of EBT3 Gafchromic films in a PSQA program for VMAT technique based on a specific routine. Moreover, a study of saturation curves was performed in order to obtain an optimal post-irradiation time for the purpose of improve the PSQA flux, besides of evaluating the costs and time expended in this kind of QA program.

It was shown that around $23 \%$ of global cases did not have success by absolute Gamma analysis. Considering that our PSQA program was stablished based on TG $119^{15}$, which warrants that, at least, $95 \%$ of cases would get success on absolute analyses, it can be seen that it has not been reproduced. In that way, it could be noticed that for RC and Prostate plans the behavior got a little bit worse: around $31 \%$ and $38 \%$ did not succeeded in absolute Gamma evaluation. In the opposite, $\mathrm{HN}$ and SBRT-SRS reached a number of only $20 \%$ and $15 \%$ of the cases reproved by absolute analysis. As studied by Marroquin et al. ${ }^{16}$, the dose uncertainty for multichannel EBT3 film analysis ranges from $7 \%$ to $1.5 \%$ for a dose interval of $0.10 \mathrm{~Gy}$ to $5 \mathrm{~Gy}$. Considering that single-channel analyses is less accurate than multichannel is, one can inferred that these deviations are higher and, then, it contributes to increase the number of cases reproved by absolute Gamma analysis. 
Based on these assumptions, taking into account the multi dose levels in $\mathrm{HN}$ cases and the characteristics of Gamma function in favoring low dose points, one can support the fact of the high HN cases number approved by absolute analyses. Moreover, as showed Marroquin et al., the uncertainty is relatively lower for dose levels ranging from $5 \mathrm{~Gy}$ to $30 \mathrm{~Gy}$ than for the ones inside of $0.10 \mathrm{~Gy}$ to $1 \mathrm{~Gy}$, which contributes to inferring the high acceptability in absolute dose evaluation.

It was evident how ADC value changes when film batch and lot vary. These discrepancies could be linked to the fact that the LINAC output factor varies as well. However, for the lot of 04/2016 no direct relationship between these features was verified. Figure 3 shows a significant shift in ADC mean values for all dose levels (or ADC values in each step), including dose level number zero, which had not been irradiated but, in the same way, presented this characteristics. It supports how relevant is performing a calibration curve for each new film box in order to taking in account the aging effect over radiochromic films. Furthermore, the film box number 55 seemed to be an outlier due its behavior for high dose levels, once the output factor had been $1.0 \%$. Therefore, care should be taken when choosing a film to be a step film.

In saturation curves analyses, it was firstly reinforced what had already been studying by others authors: the red channel for NOD evaluation is the more sensitive for doses up to $7 \mathrm{~Gy}^{1,4,13,16}$. Once for $14 \mathrm{~h}$ post-irradiation the saturation reached its maximum for almost all dose levels (including for single-channel analyses) it was chosen as being the new optimal time for scanning after film irradiation. In that way, it was shown that there is a variation of less than $2 \%$ in a period of $12 \mathrm{~h}-16 \mathrm{~h}$ after irradiation. Setting this new post-irradiation time for scanning could reduce the time delay for treatment approval and, besides of reducing the waiting time to the patient, more time would be dedicated for further tasks (e.g., planning, machine control quality, development of new techniques).

It was discussed about cost-benefit of a QA program with radiochromic films. It was shown that an institution that demands around 25 films sheets per month expends directly around US $\$ 20,000.00$ per year. Moreover, about $23 \mathrm{~h}$ per month were dedicated to its whole PSQA process based on radiochromic films. Whether film was indicated only for stereotactic and non-conventional plans (e.g. evaluate arc junction in multiple isocenters planning), which was verified that includes about $32 \%$ of total cases at our institution, it would have a directly annually cost of US $\$ 6,400.00$ and time saving nearly to 7 hours per month. The result of this time optimization could be linked to, for instance, planning two more $\mathrm{CP}$ cases or seven more SBRT/SRS plan in a month, getting some profits to the respective institution.

\section{Conclusions}

This work presented that EBT3 film dosimetry based on single-channel analysis carries a relevant lack of accuracy based on how many plans were not approved by absolute Gamma evaluation. It was evident how important is to perform a calibration curve for each film batch since there is difference between film lots due to aging effect. As part of saturation curve analysis, it was reinforced in multichannel dosimetry the sensitivity of red channel to dose levels up to 5 Gy. Once it was verified, a study over optimizing the post-irradiation time was performed for multichannel, as well as, for single-channel dosimetry. It was set an interval of $12 \mathrm{~h}-16 \mathrm{~h}$ for after irradiation scanning process. Furthermore, it could be seen how expensive PSQA with EBT3 film is and how much time consuming it is. All in all, the improvement in PSQA program at the actual institution can be seen as post-irradiation time shortening, reduced number of PSQA with film and a homemade multichannel dosimetry software that is being implemented in routine, which provides more accurate and faster analysis.

\section{Acknowledgement}

The authors thank the whole Medical Physics staff of Sírio-Libanês Hospital for directly or indirectly contributions to this whole work.

\section{References}

1.Casanova BV, Pasquino M, Russo G, Grosso P, Cante D, Sciacero $P$, et al. Dosimetric characterization and use of GAFCHROMIC EBT3 film for IMRT dose verification. J Appl Clin Med Phys. 2013;14(2):4111.

2.Aland T, Kairn T, Kenny J. Evaluation of a Gafchromic EBT2 film dosimetry system for radiotherapy quality assurance. Australas Phys Eng Sci Med. 2011;34(2):251-60.

3.Sankar A, Ayyangar KM, Nehru RM, Kurup PG, Murali V, Enke CA, Velmurugan J. Comparison of Kodak EDR2 and Gafchromic EBT film for intensity-modulated radiation therapy dose distribution verification. Med Dosim. 2006;31(4):273-82.

4. Khachonkham S, Dreindl R, Heilemann G, Lechner W, Fuchs H, Palmans H, Georg D, Kuess P. Characteristic of EBT-XD and EBT3 radiochromic film dosimetry for photon and proton beams. Phys Med Biol. 2018;63(6):65007.

5. Gafchromic radiotherapy films. Ashland, KY. [cited 2018 Apr 1] Available from: http://www.ashland.com/products/gafchromicradiotherapy-films.

6. Niroomand-Rad A, Blackwell CR, Coursey BM, et al. Radiochromic film dosimetry. AAPM Report No. 63. Recommendations of the AAPM Radiation Therapy Committee, TG No. 55. Med Phys. 1998;25(11):2093-115.

7.Saur S, Frengen J. EBT film dosimetry with flatbed CCD scanner: a novel background correction method and full dose uncertainty analysis. Med. Phys. 2008;35(7):3094-101.

8.Andres C, Del Castillo A, Tortosa R, Alonso D, Barquero R. A comprehensive study of the Gafchromic EBT2 radiochromic film. A comparison with EBT. Med Phys. 2010;37(12):6271-78.

9.Rink A, Lewis DF, Varma S, Vitkin IA, Jaffray DA. Temperature and hydration effects on absorbance spectra and radiation sensitivity of radiochromic medium. Med Phys. 2008;35(10):4545-55.

10. Lewis DF; Performance of the Vidar® Red LED Dosimetry Pro Advantage $^{\mathrm{TM}}$ : A scanner optimized for use with GAFCHROMIC $\AA$ EBT Dosimetry Film. Advanced Materials Group, International Specialty Products, Wayne, NJ. 
11. EPSON EXPRESSION 10000XL. [cited 2018 Apr 1] Available from: $\quad h$ htt://www.epson.pt/products/scanners/businessscanners/epson-expression-10000xl.

12. Pérez Azorín JF, Ramos García LI, Martí-Climent JM. A method for multichannel dosimetry with EBT3 radiochromic films. Med Phys. 2014;41(6):062101.

13. Marrazzo L, Zani M, Pallotta S, Arilli C, Casati M, Compagnucci A, Talamonti C, Bucciolini M. GafChromic( $(\mathbb{B})$ EBT3 films for patient specific IMRT QA using a multichannel approach. Phys Med. 2015;31(8):1035-1042.

14. Low DA, Harms WB, Mutic S, Purdy JA. A technique for the quantitative evaluation of dose distributions. Med Phys. 1998;25(5):656-61

15. Ezzel GA, Burmeister JW, Dogan N, LoSasso TJ, Mechalakos JG, Mihailidis D, et al. IMRT commissioning: Multiple institution planning and dosimetry comparisons, a report from AAPM Task Group 119: IMRT commissioning. Medical Physics. 2009;36(11):5359-73.

16. Marroquin EY, Herrera González JA, Camacho López MA Barajas JE, García-Garduño OA. Evaluation of the uncertainty in an EBT3 film dosimetry system utilizing net optical density. J Appl Clin Med Phys. 2016;17(5):466-481.

\section{Contact}

Alisson Henrique Dal Col

Rua Dona Adma Jafet, 115

E-mail: alisson.hcol@hsl.org.br 